\title{
Tarsocrural Instability in Cats: Combined Internal Repair and Transarticular External Skeletal Fixation
}

\author{
Meike Hammer $^{1}{ }^{10}$ Iban Irubetagoyena ${ }^{1}$ Jean-Guillaume Grand ${ }^{1}$ \\ ${ }^{1}$ Clinique Vétérinaire Aquivet, Parc D’activités Mermoz, Eysines, France \\ Address for correspondence Meike Hammer, Med Vet, Clinique \\ Vétérinaire Aquivet, Parc d'activités Mermoz, 19 Avenue de la Forêt, \\ VCOT Open 2020;3:e103-e111. \\ 33320 Eysines, France (e-mail: mhammer@vetclinics.uzh.ch).
}

\begin{abstract}
Keywords

- tarsocrural joint instability

- internal fixation

- transarticular external skeletal fixation

- cats

Objective The aim of this study was to report outcomes after combined internal repair and transarticular external skeletal fixation (TESF) for the treatment of tarsocrural joint instabilities $(\mathrm{TCl})$ in cats.

Materials and Methods Open reduction of the tarsal joint was performed followed by combined (1) internal repair (tibial/ fibular malleolar osteosynthesis or primary ligament suture and/or prosthetic ligament repair) and (2) temporary TESF. Stability of the tarsus was determined at short-term follow-up (4-8 weeks postoperatively). Short-term complications were evaluated and midterm outcome assessed by an owner telephone questionnaire.

Results Fourteen cats were included of which nine had open TCI. Median time for frame removal was 47 days. Eleven patients had satisfactory stability of the tarsus at short-term follow-up. Catastrophic complications occurred in three cats consisting of extensive skin necrosis of the paw with subsequent hindlimb amputation in two and multiple digit amputations in one cat. Major complications occurred in one cat with persistent $\mathrm{TCl}$ requiring pantarsal arthrodesis. Nine cat owners indicated a 'full or acceptable' outcome at midterm (median, 1.5 years).

Conclusion Close monitoring in the postoperative period until TESF removal is important for early identification of complications. Despite good joint stability at short-term, persistent or recurrent lameness at midterm can occur.
\end{abstract}

\section{Introduction}

Tarsocrural joint instabilities (TCI) involve malleolar fractures, collateral ligament ruptures and shearing injuries. ${ }^{1-3}$ Reconstruction of the articular surface, restoration of anatomic joint alignment and joint stabilization are paramount to optimize outcome and limit the development of osteoarthritis. ${ }^{4}$

Reduction of malleolar fractures is typically achieved by open reduction and internal fixation (ORIF) using pins and a tension band wire or a small lag screw. ${ }^{4,5}$ Treatment modalities for collateral ligament ruptures include open reduction and internal stabilization using primary ligament suture and/or prosthetic ligament reconstruction, external coaptation, transarticular external skeletal fixation (TESF) or a combination of these. ${ }^{1-3,6-8}$

received

January 15,2020

accepted after revision

July 20, 2020 10.1055/s-0040-1716350. ISSN 2625-2325.
Primary ligament suture should be attempted whenever possible. ${ }^{9}$ Unfortunately, primary repair is not always feasible particularly when there is significant soft tissue damage. Prosthetic ligament reconstruction may be used in these challenging cases to mimic the action of the ligament and ensure joint stability. An internal splint is created by placing bone anchors, screws with washers or bone tunnels at the attachment points of the ligament; these implants or tunnels serve as anchor points for suture materials. ${ }^{2,6,8,10-12}$ Clinical use of this technique in veterinary orthopaedics has only been documented in dogs in limited retrospective studies. ${ }^{13,14}$ Anatomic specificities in the cat need to be carefully considered when applying these techniques as cats only have short collateral ligaments consisting of straight and oblique branches. ${ }^{12}$ Correct implant placement is

\footnotetext{
(C) 2020 Georg Thieme Verlag KG Stuttgart · New York
}

License terms

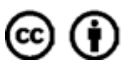


therefore especially challenging in cats due to the small bone sizes.

In addition, external supplementary support for 4 to 8 weeks after internal repair has been recommended until collateral structures begin to heal or are replaced by fibrous tissue. ${ }^{14}$ External support may be achieved using external coaptation or TESF. ${ }^{3,7}$ External coaptation is generally poorly tolerated in cats, often resulting in slippage of the bandage after shaking and soiling due to the use of litter tray. Sedation is often needed for bandage changes to reduce stress to the patient, ensure correct bandage application and guarantee staff safety. ${ }^{15}$ In contrast, TESF is well tolerated, allows for earlier weight-bearing and provides higher mechanical protection of the repaired tarsocrural joint. ${ }^{16}$ However, there is no consensus of the necessary length of treatment with an additional supportive TESF for TCI in cats to obtain definite stability. In two studies of cats with injuries of the distal tibia, tarsocrural joints, tarsus and metatarsus treated with TESF alone or ORIF with TESF, median times for frame removal were 46 and 34 days respectively. ${ }^{7,17}$ Several reports have documented outcomes of surgical techniques used for the treatment of TCI in cats. ${ }^{3,5,7,17}$ However, heterogeneity in the data reported makes direct comparison difficult.

To date, there is only sparse information available on treatment, complications and outcome in cats affected by TCI. Therefore, the aim of this study was to report the outcome of $\mathrm{TCI}$ in cats treated with a combined internal repair and temporary TESF using the Jean-Alphonse Meynard (JAM) system.

\section{Materials and Methods}

Medical records of cats presented to the Clinique Vétérinaire Aquivet during the period from 1st July 2016 to 1st May 2019 with a TCI that had been treated by open reduction and internal repair with concomitant temporary JAM-TESF were retrospectively reviewed. Inclusion criteria included patients with $\mathrm{TCI}$, complete medical records, preoperative radio- graphs, postoperative radiographs and follow-up radiographs at 4 to 8 weeks. Collection of data was a minimum of 6 months after surgery ensuring adequate time for the development of complications. ${ }^{18}$ Information collected included signalment, body weight, initiating trauma, type of $\mathrm{TCI}$ (medial, lateral or medial and lateral), other concomitant orthopaedic injuries, surgical approach, implants used, TESF configuration, time to TESF removal and complications (intra- and postoperative). Open TCI were graded according to the Gustilo-Anderson classification scheme. ${ }^{19}$

\section{Surgical Technique}

Cats were anaesthetized for surgery according to standard protocols used in our hospital. Potentiated amoxicillin-clavulanic acid (Augmentin; GlaxoSmithKline, Marly-le-Roi, France, $20 \mathrm{mg} / \mathrm{kg}$ intravenously) or cefazoline (Céfazoline; Mylan S.A.S., Saint-Priest, France; $20 \mathrm{mg} / \mathrm{kg}$ ) was administered intravenously at induction and every 90 minutes thereafter during the procedure. All procedures were performed by a boarded-certified veterinary surgeon (II or JGG). After routine preparation for aseptic surgery, animals were positioned in dorsal recumbency.

\section{Open Reduction and Internal Repair}

A standard medial or lateral approach, or a combined approach via dorsal skin incision, of the tarsus as needed was performed. A dorsal approach was used when both medial and lateral sides were injured. Medial malleolar fractures were reduced and repaired with Kirschner wires, a small lag screw or a pin and tension band wire. Lateral malleolar fractures were treated in a similar fashion (-Fig. 1). Primary repair of the ligament was attempted using a locking loop suture pattern with monofilament nonabsorbable sutures. Prosthetic ligament repair in form of an internal splint was performed in all cases with a ruptured collateral ligament using screws and spiked washers or bone tunnels at the closest attachment points of the ligament ( $\mathbf{- F i g . 1}$ ). Braided

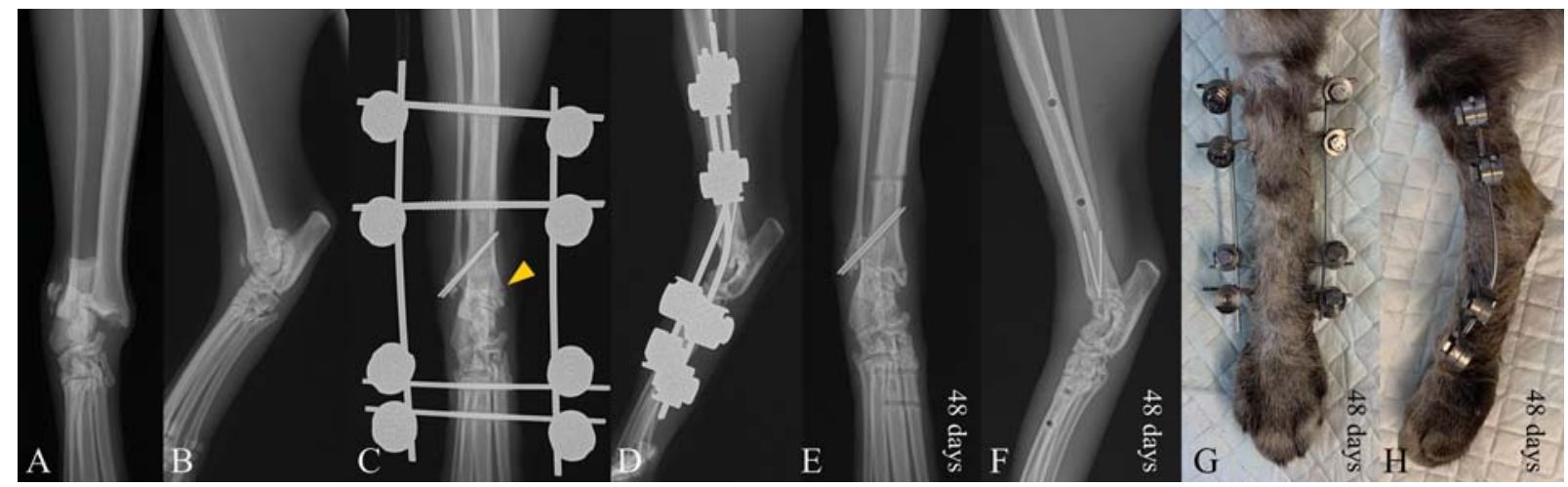

Fig. 1 Radiographs $(\mathrm{A}-\mathrm{F})$ and postoperative photographs $(\mathbf{G}, \mathrm{H})$ of a 11 -month-old $3.0 \mathrm{~kg}$ domestic short hair cat (case 14$)$ admitted with a lateral malleolar fracture and medial collateral ligament rupture (A, B). First, the fracture was stabilized by open reduction and internal fixation using two $0.8 \mathrm{~mm}$ Kirschner wires (C, D). Then, the medial tibiotarsal compartment was stabilized by internal splinting using two bone tunnels through the medial malleolus (arrow) and talus as anchor points for polyethylene suture material (C, D). Note, the talar bone tunnel is not visible on the radiographs. Finally, a temporary Jean-Alphonse Meynard-transarticular external skeletal fixation was applied. Two full pins were placed proximal and distal to the tarsocrural joint. Accurate reduction was obtained, and alignment was restored (C, D). Short-term follow-up radiographs obtained at 48 days postoperatively demonstrated clinical union of the lateral malleolar fracture (E, $\mathrm{F}$ ). After removal of the connecting bars, the patient was considered to have satisfactory stability of the tarsal joint by manual manipulations, allowing for definitive frame removal $(\mathbf{G}, \mathbf{H})$. 
or monofilament nonabsorbable sutures were used to augment or replace the damaged ligament. The choice of suture materials was at the discretion of the surgeon. Sutures were placed in a figure of eight around screws with washers or through bone tunnels and were tightened at a joint angle of $\sim 115$ to 125 degrees of extension. Routine wound closure of the surgical approach was performed. Axial alignment was assessed and successful stabilization of the tarsocrural joint was confirmed by systematic manipulations of the joint stressed in mediolateral, dorsoplantar and rotary planes.

\section{JAM-TESF}

A JAM external skeletal fixation system, capable of holding fixation pins from 1.5 to $3.0 \mathrm{~mm}$ in diameter, was used throughout. External support was provided for 4 to 8 weeks after surgery using a medially placed type Ia or type IIa JAMTESF. ${ }^{20}$ Positive-centrally (for type IIa TESF) or end-threaded (for type Ia TESF) pins were used and were applied percutaneously in all cases without predrilling. Two or three pins were placed in the tibia and two or three pins were placed in the tarsal and/or metatarsal bones. Curved connecting bars were used to reproduce the normal joint standing angle and were positioned with the bend directly over the center of the head of the talus. No diagonal bars were used (-Fig. 1).

Radiographic evaluation was performed immediately after JAM-TESF placement. A protective bandage was applied for 2 to 3 days to limit postoperative swelling, followed by a lightweight bandage only around the TESF frame to reduce the risk of self-injury from sharp pins (-Fig. 2). Regular bandage changes were performed every 7 to 10 days until frame removal.

\section{Short-Term Follow-Up}

Clinical and radiographic follow-up was scheduled at 4 to 8 weeks and thereafter as required. All patients were reviewed

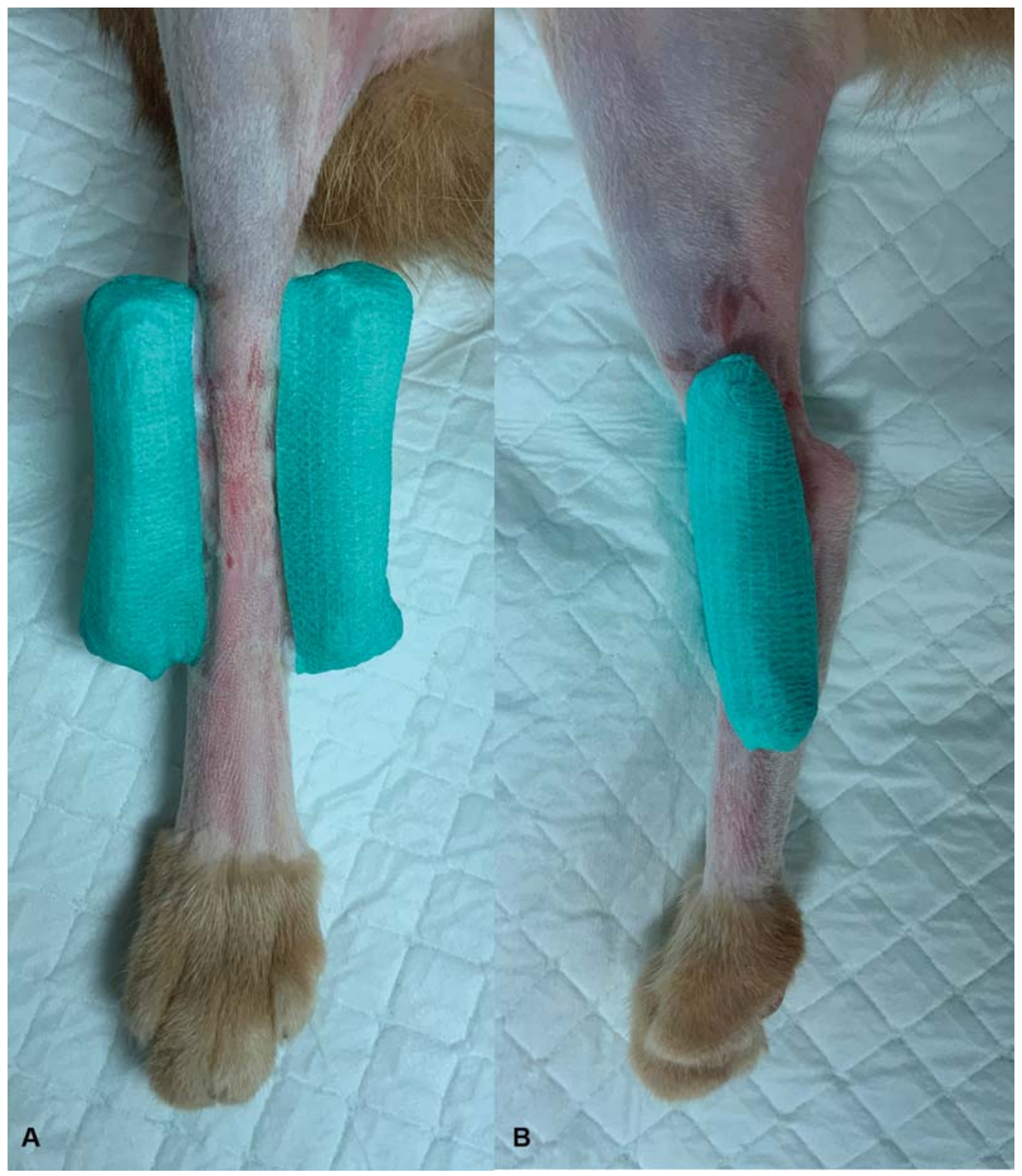

Fig. 2 Photographs (A, B) showing a light-weight bandage applied only around the transarticular external skeletal fixation frame to reduce the risk of self-injury from sharp pins while allowing early weight-bearing. 
at the author's institution by one of the two board-certified surgeons (II or JGG) or an experienced surgical resident under their supervision. The timing of final frame removal was determined by (1) radiological assessment of fracture union (if indicated) and (2) demonstration of stability of the tarsocrural joint by manual manipulation after removal of the connecting bars under sedation. Clinical records were evaluated for the assessment of range of motion, stability, swelling, crepitus or any signs of discomfort. Radiographs at each time point were assessed for fracture reduction, evidence of implant migration, bone union and complications associated with the internal implants or JAM-TESF. Complications were reported as previously defined by Cook et al as catastrophic, major and minor. ${ }^{18}$ Time from surgery to complication was noted, and if $>1$ complication occurred in 1 patient, each was considered separately.

\section{Midterm Outcome}

Midterm follow-up was assessed by a modified owner-answered telephone questionnaire (-Supplementary Material) at the time of data collection as previously published. ${ }^{21}$ The owners were asked to subjectively grade the outcome of their animal based on the grading system proposed by Cook et al as 'full' (performs all normal activities that were done prior to surgery), 'acceptable' (prior activity level not fully regained but good quality of life/function) and 'unacceptable' (permanent constraint). ${ }^{18}$

\section{Data Analysis}

Data were entered into a spreadsheet (Excel, version 1906, Microsoft Corp, Redmond, Washington. Descriptive statistics were calculated, with median and range reported. Data frequency in each category was reported.

\section{Results}

Fourteen cats met the inclusion criteria (-Table 1). Median age was 5.5 years (range, 8 months to 15 years) and median bodyweight was $4.7 \mathrm{~kg}$ (range, $3.0-8.2 \mathrm{~kg}$ ). Road traffic accident was the cause of $\mathrm{TCI}$ in seven cases. The remaining seven cases were due to domestic accident $(n=3)$, unknown trauma $(n=2)$, dog bite $(n=1)$ and fall $(n=1)$. Concomitant orthopaedic injuries were found in three cats and included contralateral craniodorsal coxofemoral luxation $(n=1)$, sacroiliac luxation $(n=1)$ and ilial fracture $(n=1)$. Median time from trauma to surgery was 2 days (range, $0-7$ days). Eleven cats presented a complete luxation of the tarsocrural joint and three cats a tarsocrural instability. Eleven cases had concomitant medial and lateral, two had lateral and one had medial TCI ( - Table 1). Eight cases had a lateral, one a medial and two had concomitant lateral and medial malleolar fractures. Nine TCI were open, of which six were classified as grade 1, two as grade 2 and one as grade $3 \mathrm{~A}$. Bacterial cultures were performed from three joints. Enterobacter cloacae was isolated in one case. Bacterial culture failed to yield a positive culture in the remaining cases.

\section{Surgical Procedure}

Primary ligament suture was performed in three cases. Medial prosthetic ligament reconstruction was performed in 10 cases by the means of an internal splint using bone tunnels $(n=9)$ and screws with spiked washers $(n=1)$. Lateral prosthetic ligament repair was performed in two cases using bone tunnels exclusively. The TCI was stabilized with a type Ila tibio-tarso-metatarsal JAM-TESF in 6, a type Ila tibio-metatarsal JAM-TESF in 7 and a type Ia medially placed tibio-tarso-metatarsal JAM-TESF in $1 / 14$ cats. Implants used for internal repair are reported in - Table 1. Perioperative complications were noted in $1 / 14$ cats on immediate postoperative radiographs, consisting of cis-cortex pin tract fracture of one JAM-TESF pin. No revision surgery was performed in this case.

\section{Short-Term Follow-Up}

\section{Clinical Assessment}

Median time to follow-up was 47 days (range, 34-67 days). The JAM-TESF frames were well tolerated in all cats. After removal of the connecting bars under sedation, 10 of 12 patients were considered to have satisfactory stability of the tarsal joint by manual manipulation, allowing for definitive frame removal. In one cat (case 4 ), the tarsal joint was still considered unstable. In another (case 7), the JAM-TESF was left in place 3 more weeks as a precaution as the cat was severely overweight. Overall, median time to frame removal was 47 days (34-91 days) (-Table 2 ).

\section{Complications}

Overall postoperative complications occurred in 7/14(50.0\%) cases (-Table 2). Catastrophic complications were reported in three cats; two cats had extensive tarsal and digit skin necrosis with loss of deep pain sensation by the 15th and 31th postoperative day requiring hindlimb amputation (cases 4 and 5); one cat (case 12) developed skin necrosis on phalanges III to $\mathrm{V}$ and was treated by multiple digit amputations. Major complications occurred in one cat (case 6) with persistent TCI subsequently treated by pantarsal arthrodesis. All catastrophic and major complications were encountered with open TCI. Minor complications occurred in three cats including pin tract osteomyelitis $(n=1)$, pressure sores due to bandages $(n=1)$ and fracture of the 5 th metatarsal bone $(n=1)$.

\section{Midterm Outcome}

Twelve owners provided questionnaire response during telephone interview at a median postoperative time of 1 year, 5 months (range, 8 months to 3 years, 7 months) (-Table 3 ). Of these, one was of a cat that had been amputated due to severe complications (case 4 ) but reported a good quality of life. The remaining 11 owners rated the outcome as full in five, acceptable in four and unacceptable in two cats. Ongoing lameness was reported in six cats; four had intermittent lameness and two had permanent lameness. 
Table 1 Preoperative and operative patient details

\begin{tabular}{|c|c|c|c|c|c|c|}
\hline Case & Signalment & $\begin{array}{l}\text { Initiating } \\
\text { trauma }\end{array}$ & $\begin{array}{l}\text { Open } \\
\text { TCl } \\
\text { (grade) }\end{array}$ & $\begin{array}{l}\text { Tarsal injury } \\
\text { (instability/ } \\
\text { luxation) }\end{array}$ & Surgical procedure; implants used & $\begin{array}{l}\text { JAM-TESF configuration; } \\
\text { pin diameter; bar diameter }\end{array}$ \\
\hline 1 & $\begin{array}{l}\text { DSH, mn, } 2 \text { y } \\
8 \mathrm{mo}, 5.6 \mathrm{~kg}\end{array}$ & HRI & 1 & $\begin{array}{l}\mathrm{LMF} \\
\text { MCLR } \\
\text { (luxation) }\end{array}$ & $\begin{array}{l}\text { Not applicable }{ }^{*} \\
\left.\text { PLS (Prolene }{ }^{\mathrm{a}} 0\right)+ \text { PLR (Prolene }{ }^{\mathrm{a}} 0 \\
\text { through a MM and talus bone } \\
\text { tunnel) }\end{array}$ & $\begin{array}{l}\text { Type Ila; TTM }(3+1+2) \text {; Pd: } \\
1.5 \text { mm; Bd: } 3 \text { mm }\end{array}$ \\
\hline 2 & $\begin{array}{l}\mathrm{DSH}, \mathrm{mn}, 15 \mathrm{y} \\
3 \mathrm{mo}, 4.0 \mathrm{~kg}\end{array}$ & RTA & - & $\begin{array}{l}\text { LCLR } \\
\text { (instability) }\end{array}$ & $\begin{array}{l}\text { PLR (Monosyn }{ }^{\mathrm{b}} 2 / 0 \text { through a LM } \\
\text { and calcaneus bone tunnel) }\end{array}$ & $\begin{array}{l}\text { Type la; TTM }(2+1+1) \text {; Pd: } 2 \text { mm; } \\
\text { Bd: } 2 \text { mm }\end{array}$ \\
\hline 3 & $\begin{array}{l}\text { DSH, fn, } 8 \mathrm{mo} \text {, } \\
3.2 \mathrm{~kg}\end{array}$ & RTA & - & $\begin{array}{l}\text { MMF } \\
\text { LCLR } \\
\text { (luxation) }\end{array}$ & $\begin{array}{l}\text { ORIF; Pd: } 1.25 \mathrm{~mm}+1 \mathrm{~mm} \text {; Cw: } \\
0.8 \mathrm{~mm} \\
\text { PLR (Dafilon` } 1 \text { through a LM and } \\
\text { calcaneus bone tunnel) }\end{array}$ & $\begin{array}{l}\text { Type Ila; TTM }(3+1+2) \text {; Pd: } \\
1.5 \text { mm; Bd: } 2 \text { mm }\end{array}$ \\
\hline 4 & $\begin{array}{l}\text { DSH, fn, } 6 \text { y } \\
11 \mathrm{mo}, 5.0 \mathrm{~kg}\end{array}$ & RTA & 2 & $\begin{array}{l}\text { LMF } \\
\text { MCLR } \\
\text { (luxation) }\end{array}$ & $\begin{array}{l}\text { ORIF; Pd: } 1 \mathrm{~mm}+1 \mathrm{~mm} \\
\left.\text { PLS (Prolene } \mathrm{a}^{\mathrm{a}} 2 / 0\right)+\mathrm{PLR} \text { (Prolene } \\
2 / 0 \text {; around a } 2 \mathrm{~mm} \text { tibial screw with } \\
\text { washer and through a talus bone } \\
\text { tunnel) }\end{array}$ & $\begin{array}{l}\text { Type Ila; TM }(2+2) \text {; Pd: } 1.5 \text { mm; Bd: } \\
2 \mathrm{~mm}\end{array}$ \\
\hline 5 & $\begin{array}{l}\mathrm{DSH}, \mathrm{fn}, 9 \mathrm{y} \\
7 \mathrm{mo}, 4.4 \mathrm{~kg} \\
\end{array}$ & $\mathrm{Da}$ & 1 & $\begin{array}{l}\text { MCLR } \\
\text { (luxation) }\end{array}$ & $\begin{array}{l}\text { PLR (Prolene }{ }^{\mathrm{a}} 0 \text { around MM and talus } \\
2 \mathrm{~mm} \text { screws with washers) }\end{array}$ & $\begin{array}{l}\text { Type Ila; TM (3+2); Pd: } 2 \mathrm{~mm} \text { (tib- } \\
\text { ia), } 1.5 \mathrm{~mm} \text { (metatarsus); Bd: } 2 \mathrm{~mm}\end{array}$ \\
\hline 6 & $\begin{array}{l}\mathrm{DSH}, \mathrm{mn}, 4 \mathrm{y} \\
1 \mathrm{mo}, 7.6 \mathrm{~kg}\end{array}$ & RTA & 3 & $\begin{array}{l}\text { LMF } \\
\text { MCLR } \\
\text { (luxation) }\end{array}$ & $\begin{array}{l}\text { ORIF; Pd: } 1.0 \mathrm{~mm}+1.25 \mathrm{~mm} \\
\text { PLR (Dafilon }{ }^{\mathrm{c}} 1 \text { through a MM and } \\
\text { talus bone tunnel) }\end{array}$ & $\begin{array}{l}\text { Type lla; TTM }(2+1+1) ; \text { Pd: } 2 \mathrm{~mm} \\
\text { (tibia), } 1.5 \mathrm{~mm} \text { (tarsus and meta- } \\
\text { tarsus); Bd: } 2 \mathrm{~mm}\end{array}$ \\
\hline 7 & $\begin{array}{l}\text { DSH, fn, } 9 \mathrm{y} \\
7 \mathrm{mo}, 8.2 \mathrm{~kg}\end{array}$ & $\mathrm{Da}$ & - & $\begin{array}{l}\mathrm{LCLR} \\
\text { (instability) }\end{array}$ & $\begin{array}{l}\text { PLR (Ethibond }{ }^{\mathrm{d}} 3 \text { through a LM and } \\
\text { calcaneus bone tunnel) }\end{array}$ & $\begin{array}{l}\text { Type Ila; TTM }(3+1+2) ; \text { Pd } 2 \mathrm{~mm} \\
\text { (tibia), } 1.5 \mathrm{~mm} \text { (talus, calcaneus, } \\
\text { metatarsus); Bd } 2 \mathrm{~mm}\end{array}$ \\
\hline 8 & $\begin{array}{l}\mathrm{DSH}, \mathrm{mn}, 1 \mathrm{y} \\
11 \mathrm{mo}, 5.4 \mathrm{~kg}\end{array}$ & RTA & 2 & $\begin{array}{l}\text { MCLR } \\
\text { LCLR } \\
\text { (instability) }\end{array}$ & $\begin{array}{l}\text { PLR (Dafilon }{ }^{c} 1 \text { through a MM and } \\
\text { talar bone tunnel) } \\
\text { PLR (Dafilon }{ }^{c} 1 \text { through a LM and } \\
\text { calcaneus bone tunnel) }\end{array}$ & $\begin{array}{l}\text { Type Ila; TM ( } 2+2) ; \text { Pd } 2 \text { mm (tibia), } \\
1.5 \text { mm (metatarsus); Bd } 2 \text { mm }\end{array}$ \\
\hline 9 & $\begin{array}{l}\mathrm{DSH}, \mathrm{mn}, 11 \mathrm{y} \\
2 \mathrm{mo}, 6.3 \mathrm{~kg}\end{array}$ & Ukn & - & $\begin{array}{l}\text { LMF } \\
\text { MCLR } \\
\text { (luxation) }\end{array}$ & $\begin{array}{l}\text { ORIF; Pd } 1 \mathrm{~mm}+1 \mathrm{~mm} \text {; } \\
\text { PLS (Monosyn } 2 / 0 \text { ) } \\
\text { PLR (Ethibond }{ }^{\mathrm{d}} 3 \text { through a MM and } \\
\text { talar bone tunnel) }\end{array}$ & $\begin{array}{l}\text { Type Ila; TM }(2+2) \text {; Pd } 1.5 \text { mm; } \\
\text { Bd } 2 \text { mm }\end{array}$ \\
\hline 10 & $\begin{array}{l}\mathrm{DSH}, \mathrm{fn}, 2 \mathrm{y} \\
2 \mathrm{mo}, 3.2 \mathrm{~kg}\end{array}$ & $\mathrm{Db}$ & 1 & $\begin{array}{l}\text { LMF } \\
\text { MCLR } \\
\text { (luxation) }\end{array}$ & $\begin{array}{l}\text { ORIF; Pd } 1 \mathrm{~mm}+0.8 \mathrm{~mm} \\
\text { PLR (Monosyn } 1 \text { through a MM and } \\
\text { talar bone tunnel) }\end{array}$ & $\begin{array}{l}\text { Type Ila; TM }(3+2) \text {; Pd } 1.5 \text { mm; } \\
\text { Bd } 2 \text { mm }\end{array}$ \\
\hline 11 & $\begin{array}{l}\mathrm{DSH}, \mathrm{mn}, 4 \mathrm{y} \\
5.2 \mathrm{~kg}\end{array}$ & RTA & 1 & $\begin{array}{l}\text { LMF } \\
\text { MCLR } \\
\text { (luxation) }\end{array}$ & $\begin{array}{l}\text { ORIF; } 2 \mathrm{~mm} \text { screw, Pd } 1 \mathrm{~mm} \\
\text { PLR (Prolene } 2 / 0 \text { through a MM and } \\
\text { talar bone tunnel) }\end{array}$ & $\begin{array}{l}\text { Type Ila; TTM }(3+1+1) \text {; Pd } 1.5 \text { mm; } \\
\text { Bd } 2 \text { mm }\end{array}$ \\
\hline 12 & $\begin{array}{l}\text { DSH, fn, } 9 \mathrm{y} \\
1 \mathrm{mo}, 3.9 \mathrm{~kg}\end{array}$ & Ukn & 1 & $\begin{array}{l}\text { LMF } \\
\text { MCLR } \\
\text { (luxation) }\end{array}$ & $\begin{array}{l}\text { ORIF; } 1.5 \mathrm{~mm} \text { screw }+ \text { Pd } 0.8 \mathrm{~mm} \\
\text { PLR (Prolene } 2 / 0 \text { through a MM and } \\
\text { central tarsal bone tunnel) }\end{array}$ & $\begin{array}{l}\text { Type Ila; TTM }(2+1+1) \text {; Pd } 1.5 \text { mm; } \\
\text { Bd } 2 \text { mm }\end{array}$ \\
\hline 13 & $\begin{array}{l}\text { DSH, fn, } 7 \mathrm{y} \\
6 \mathrm{mo}, 3.9 \mathrm{~kg}\end{array}$ & Da & 1 & $\begin{array}{l}\text { MMF } \\
\text { LMF } \\
\text { (luxation) }\end{array}$ & $\begin{array}{l}\text { ORIF; Pd } 1 \mathrm{~mm}+1 \mathrm{~mm} \\
\text { ORIF; Pd } 1 \mathrm{~mm}\end{array}$ & $\begin{array}{l}\text { Type Ila; TM }(2+2) ; \text { Pd } 2 \text { mm (tibia), } \\
1.5 \text { mm (metatarsus); Bd } 2 \text { mm }\end{array}$ \\
\hline 14 & $\begin{array}{l}\text { DSH, fn, } 11 \mathrm{mo}, \\
3.0 \mathrm{~kg}\end{array}$ & RTA & - & $\begin{array}{l}\text { LMF } \\
\text { MCLR } \\
\text { (luxation) }\end{array}$ & $\begin{array}{l}\text { ORIF; Pd } 0.8 \mathrm{~mm}+0.8 \mathrm{~mm} \\
\text { PLR (Ethibond }{ }^{\mathrm{d}} 3 \text { through a MM and } \\
\text { talar bone tunnel) }\end{array}$ & $\begin{array}{l}\text { Type Ila; TM (2+2); Pd } 2 \text { mm (tibia), } \\
1.5 \mathrm{~mm} \text { (metatarsus); Bd } 2 \text { mm }\end{array}$ \\
\hline
\end{tabular}

Abbreviations: Bd, bar diameter; Da, domestic accident; Db, dog bite DSH, domestic short-haired cat; fn, female neutered; HRI, high rise injury; JAMTESF, Jean-Alphonse Meynard transarticular external skeletal fixation; LCLR, lateral collateral ligament rupture; LM, lateral malleolus; LMF, lateral malleolar fracture; MCLR, medial collateral ligament rupture; MM, medial malleolus; MMF, medial malleolar fracture; mn, male neutered; ORIF, open reduction and internal fixation; Pd, pin diameter; PLR, prosthetic ligament reconstruction; PLS, primary ligament suture; RTA, road traffic accident; TM, tibio-metatarsal; TTM, tibio-tarso-metatarsal; Ukn, unknown.

Note: Age in years (y) and months (mo).

*Not reconstructible LMF (complete lateral malleolus abrasion).

aPolypropylene (Prolene, Ethicon, Johnson \& Johnson International).

bolyglyconate (Mononosyn, B. Braun ${ }^{\circledR}$, Johnson \& Johnson International).

'Polyamide (Dafilon, B. Braun, Rubi, Spain).

${ }^{\mathrm{d} C o a t e d}$ polyester (Ethibond EXCEL, Ethicon, Johnson \& Johnson International). 
Table 2 Short-term follow-up data (4-8 weeks postoperatively) including clinical and radiographic assessments

\begin{tabular}{|c|c|c|c|c|}
\hline Case & $\begin{array}{l}\text { Time for frame } \\
\text { removal (d) }\end{array}$ & $\begin{array}{l}\text { Clinical } \\
\text { assessment } \\
\text { of tarsocrural } \\
\text { joint stability }\end{array}$ & Radiographic recheck & $\begin{array}{l}\text { Complications (catastrophic, } \\
\text { major, minor); specific comments }\end{array}$ \\
\hline 1 & 47 & $\mathrm{NI}$ & WNL & None \\
\hline 2 & 41 & $\mathrm{NI}$ & WNL & $\begin{array}{l}\text { MiC; pressure sore due to bandage with } \\
\text { resolution by second intention healing }\end{array}$ \\
\hline 3 & 47 & $\mathrm{NI}$ & WNL with RU of MMF & None \\
\hline 4 & NA & NA & $\mathrm{NA}$ & $\begin{array}{l}\text { CC; progressive skin necrosis of the paw with } \\
\text { loss of deep pain sensation and subsequent } \\
\text { hind limb amputation on day } 15\end{array}$ \\
\hline 5 & NA & NA & NA & $\begin{array}{l}\text { CC; ischemic necrosis of the dorsal metatarsal } \\
\text { skin with loss of deep pain sensation on } \\
\text { day } 17 \text { and subsequent hindlimb amputation } \\
\text { on day } 31\end{array}$ \\
\hline 6 & 51 & $\mathrm{PTCl}$ & WNL with RU of LMF & $\begin{array}{l}\text { MaC; wound and implant infection after TESF } \\
\text { removal (Enterococcus faecalis), recurrence } \\
\text { of TCI } 8 \text { weeks postoperative (implant } \\
\text { removal, open wound management; } \\
\text { arthrodesis with modified type II ESF } \\
12 \text { weeks postoperative) }\end{array}$ \\
\hline 7 & 91 & $\mathrm{NI}$ & $\begin{array}{l}\text { Fracture of metatarsus } V \text { at the } \\
\text { pin-bone interface, intra-operative } \\
\text { fractures of the cis-cortex of tibial } \\
\text { pins with mild callus formation, }\end{array}$ & MiC; conservative treatment \\
\hline 8 & 55 & $\mathrm{NI}$ & WNL & None \\
\hline 9 & 67 & $\mathrm{NI}$ & WNL with RU of LMF & None \\
\hline 10 & 50 & $\mathrm{NI}$ & WNL with RU of LMF & None \\
\hline 11 & 40 & $\mathrm{NI}$ & WNL with RU of LMF & None \\
\hline 12 & 34 & $\mathrm{NI}$ & $\begin{array}{l}\text { RU of LMF, mild bone lysis around } \\
\text { LM screw, moderate OA }\end{array}$ & $\begin{array}{l}\text { CC; necrosis of phalanges III-V and dorsal } \\
\text { metatarsal skin wound } 2 \text { weeks postopera- } \\
\text { tively treated with phalangeal amputations }\end{array}$ \\
\hline 13 & 43 & $\mathrm{NI}$ & $\begin{array}{l}\text { RU of LMF, osteomyelitis tibia, } \\
\text { bone lysis around MM implants }\end{array}$ & $\begin{array}{l}\text { MiC; treatment: Cephalexin and modified } \\
\text { Robert Jones bandage for } 1 \text { week after TESF } \\
\text { removal }\end{array}$ \\
\hline 14 & 48 & $\mathrm{NI}$ & RU of LMF; mild OA & None \\
\hline
\end{tabular}

Abbreviations: CC, catastrophic complication; LM, lateral malleolus; LMF, lateral malleolar fracture; MaC, major complication; MiC, minor complication; MM, medial malleolus; MMF, medial malleolar fracture; NA, not applicable; NI, no instability; OA, osteoarthritis; PTCI, persistent tarsocrural joint instability; RU, radiographic union; TCI, tarsocrural joint instability; TESF, transarticular external skeletal fixation; WNL, within normal limits.

${ }^{\mathrm{a} B y}$ manual manipulations after removal of TESF bars under sedation.

\section{Discussion}

In this study, the overall outcome following repair of TCI in cats by combining open reduction and internal repair with temporary JAM-TESF was acceptable. Despite good initial joint reduction and stabilization, and satisfactory stability of the tarsocrural joint at short-term in 10/12 patients, persistent lameness at midterm was an important finding in half of the cases. Nevertheless, midterm outcome was considered as 'fully functional or acceptable' in 10/12 patients and only 2/12 had 'unacceptable' function according to the owners. The JAM-TESF therefore showed to be an adequate means for adjunct treatment of $\mathrm{TCI}$ in cats. It performed favourable when considering necessary implant stability while being less bulky in our reported light-weight fashion than other previously published configurations and systems, and therefore offered an improved comfort to the patient. ${ }^{1,7}$

Primary internal repair was used for three purposes: first, to re-establish the congruency and stability of the joint; second, to maintain good articular reduction before TESF placement; and third, to mitigate the need for heavy and bulky TESF frames. Internal repair of the TCI may be particularly challenging due to the complex anatomy of this region, the small bone sizes and the difficulties to achieve an isometrically placed prosthesis. In this study, transosseous tunnels were used in most of the cases for prosthetic ligament reconstruction. This technique has been described to allow more accurate placement of the prosthetic material at 
Table 3 Midterm outcome assessed by owner questionnaire

\begin{tabular}{|l|l|l|l|l|l|l|}
\hline Case & Status & $\begin{array}{l}\text { Follow-up } \\
\text { time (y) }\end{array}$ & $\begin{array}{l}\text { Ongoing } \\
\text { lameness/ } \\
\text { stiffness }\end{array}$ & $\begin{array}{l}\text { Subjective } \\
\text { outcome }\end{array}$ & $\begin{array}{l}\text { Overall owner } \\
\text { satisfaction } \\
\text { (satisfied, fair, } \\
\text { disappointed) }\end{array}$ & Specific owners' comments \\
\hline 1 & Alive & 3.5 & $\mathrm{~N}$ & Full & Satisfied & \\
\hline 2 & Dead & 3.4 & $\mathrm{~N}$ & Full & Satisfied & \\
\hline 3 & Alive & 2.8 & Y, intermittent & Acceptable & Satisfied & \\
\hline 4 & Alive & 2.4 & NA & NA & NA & Good quality of life although amputated \\
\hline 7 & Alive & 0.8 & N & Acceptable & Satisfied & Moderate plantigrade stance, \\
severely overweight
\end{tabular}

Abbreviations: N, no; NA, not applicable; Y, yes.

proximal and distal attachment sites for the collateral ligaments than can be achieved with the use of screws. ${ }^{6}$ Furthermore, use of bone tunnels avoids the need for cumbersome orthopaedic implants especially in cats, which if they are not correctly placed, may cause soft tissue irritations (i.e. screws with spiked washers), and mechanical conflicts with malleolus or articular surfaces. Multifilament materials have been considered to induce a high rate of postoperative infection. ${ }^{13}$ However, coated polyester material was used in our study in three cases of closed TCI without any clear negative impact. Non-absorbable multifilament orthopaedic sutures are thought to be stronger, stiffer and undergo less elongation than comparably sized monofilament sutures. Hence, they may be well suited for prosthetic ligament reconstruction. ${ }^{22}$

The type IIa TESF was the most commonly used frame in $13 / 14$ cats. As only one cat was treated with a type Ia frame, we are unable to recommend whether two pins on either side of the tarsocrural joint were sufficient. The type Ila TESF provides greater mechanical stability compared with type Ia and may avoid problems associated with premature pin loosening. ${ }^{23}$ Because type Ila TESF may be bulky in cats, we tried to alleviate as much as possible our constructs by placing only two pins from either side of the tarsocrural joint in some cases and by using curved lateral connecting bars without additional triangulation bars. There remains debate as to the number of pins required proximal and distal to the tarsocrural joint. Recommendations vary from two to three pins. ${ }^{7,14,17}$ In the study published by Kulendra et al, the number of fixation pins inserted proximally and distally to the tarsocrural joint respectively varied between $2+2$ up to $5+5$, with the majority of cats having three or more pins on one or both sides of the joint. ${ }^{17}$ Due to the limited number of cases, no conclusion could be drawn whether two or three pins would perform superior over the other. Kulendra et al nevertheless recommended three pins proximal and distal to the joint in this medially placed type I TESF with an additional connecting bar ('A-frame'). Considering the superiority of type II TESF in cats with $\mathrm{TCl}^{7}$ as well as aspects of patient comfort, a type IIa TESF with two pins proximal and two distal to the joint may be less interfering with walking and normal cat behaviour while still providing sufficient stability than a medially placed type Ia $3+3 \mathrm{~A}$-frame configuration. Further, using the least number of pins necessary might be advantageous to avoid compromise of blood supply. Nevertheless, further investigations are needed to prove these hypotheses.

Predrilling has been recommended for the placement of external fixators. ${ }^{24}$ We exempted from this due to the small feline bone size. Based on our study, the use of two pins proximal and distal to the tarsocrural joint gave good clinical results and no implant failure was reported in any of the cases. This is in contrast to Kulendra's report in which a high number of implant-related complications was found when two pins were used proximal and distal to the tarsocrural joint in type I TESF. ${ }^{17}$ In this study, half of the TESF had an additional bar connecting the most proximal and distal aspect ('A-frame'). ${ }^{17}$ Also, four different TESF systems (IMEX-SK, Kirschner-Ehmer (KE), epoxy putty, IMEX-SK combined with epoxy putty) were used precluding a direct comparison. Neither the KE or IMEX-SK clamps nor the JAM clamps have been mechanically tested to date for this indication. To address these difficulties, only one TESF system has been used in our study with exclusively positivethreaded pins to improve frame stability as previously recommended. ${ }^{25}$ All clamps used were not reused. We did 
not report any implant-related complications with the JAMTESF, suggesting its suitability for temporary stabilization of $\mathrm{TCI}$ in cats after internal repair. Further investigations are needed for making recommendations regarding the exact frame type and number of pins necessary for this indication.

The overall complication rate $(50 \%)$ in this study was comparable to previous reports. ${ }^{71}$ Injuries to the tarsocrural joint are commonly caused by shearing injuries due to its sparse soft tissue coverage which has been reported in dogs after road traffic accidents resulting in a combination of injuries to the skin, collateral ligaments and bony structures. ${ }^{10}$ Attention needs to be paid particularly on these open TCI as all catastrophic complications in our study occurred in this group. Significant differences in wound healing between species have been found with rates of wound contraction, epithelialization and total healing being reduced in cats compared with dogs. ${ }^{26}$ Given the even thinner skin and the more fragile vascularization in cats, special attention needs to be paid on the occurrence of complications during the prolonged healing period. ${ }^{27}$ Catastrophic complications were reported in three cats in our study and were all related to the soft tissues; two cats had extensive tarsal and digit skin necrosis with loss of deep pain sensation and one cat developed skin necrosis on phalanges III to $\mathrm{V}$ and was treated by multiple digit amputations. Primary soft tissue injury and additional surgical trauma may impair the fragile vascularization of the distal limb leading to plantar necrosis as reported in dogs following pantarsal arthrodesis and in cats after tibial/fibular malleoli fracture repair. ${ }^{5,28}$ The reasons for necrosis of the paw in case 4 were most likely secondary to the severity of the initial injury as the viability of the limb was questionable at the time of surgery. Postoperative complications may have also developed from bandage application. The reason for necrosis of the digits in case 12 remains unknown, but bandaging errors could not be ruled out as the cat had been treated by the referring veterinarian until final frame removal. Bandage-related soft tissue complications have been reported in up to $63 \%$ of cases treated for an orthopaedic condition ranging from mild erythema to full-thickness skin lesions. ${ }^{29}$ A protective bandage was applied after surgery in our cases to limit soft tissue swelling followed by a light-weight bandage only around the TESF frame (-Fig. 2) until frame removal to prevent self-trauma from sharp edges of the TESF. In contrast to external coaptation, the use of TESF with the illustrated protective bandage was well tolerated in all patients and offered improved comfort. Nevertheless, some surgeons advise against the use of bandages on external skeletal fixators except for the immediate postoperative period. Adequate training is needed to prevent bandage injuries. ${ }^{30}$

Persistent or recurrent lameness at midterm in half of the cats as reported by the owners during questionnaire was an important finding and has not been reported previously. Considering that $11 / 14$ cats had complete luxations of the tarsocrural joint and 9/14 been open, a poorer outcome can be expected. This is in contrast to the reported excellent outcome in cats with isolated tibial/fibular malleoli frac- tures. ${ }^{5}$ Unfortunately, the reasons for recurrent or persistent lameness are unknown. Overall, early recognition and treatment of complications are important as they had a negative impact on outcome and overall owner satisfaction in our study.

The median time to TESF removal was 47 days in the current study, which is comparable to the report by Kulendra et al (median, 46 days) but more than reported by Owen et al (mean, 34 days). ${ }^{717}$ There remains debate regarding the duration of TESF treatment. Decreased synovial fluid production and range of motion and the initiation of osteoarthritis represent the most functionally recognizable drawbacks of long-term TESF. ${ }^{16,31,32}$ Based on our study, the decision to immobilize the injured joints for 4 to 8 weeks was empirical and seemed to be a 'good' compromise for achieving sufficient stability while minimizing deleterious effects.

Limitations of this study are those inherent to its retrospective nature. Due to the limited number of cases, only descriptive statistics were performed. Minor complications might have been underdiagnosed as bandage changes were often performed by the referring veterinarian. Two cases were also lost to follow-up at the time of owner questionnaire of which one was an amputated cat; however, 11/12 (when excluding the two amputated cats) have equivalent followup as the 32 cases reported by Kulendra et al. ${ }^{17}$ Our study has a long midterm follow-up (median, 1.5 years) and further used a clinical methodology, as per current recommendations. The lack of clinical and radiographic examination or objective gait assessment such as force plate analysis at mid- and long-term follow-up represents another limitation. The occurrence and degree of osteoarthritis, range of motion of the joint or recurrence of joint instability remain therefore unknown. A recheck was offered for all cats that did not have a full recovery at the time of owner questionnaire but was declined by the owners. Therefore, the cause of the plantigrade stance of two cats at midterm follow-up remains unknown. Also, the reason for the unacceptable function of case 12 is unknown but may be attributed to the multiple digit amputation rather than the tarsal repair according to the owner. Owner-based questionnaires have been shown to be a valuable tool for follow-up assessment in dogs, ${ }^{33}$ but to the authors' knowledge, no feline questionnaire has been validated.

\section{Conclusion}

In conclusion, the use of open reduction and internal repair combined with temporary JAM-TESF provided an acceptable short- and midterm outcome in the majority of cats. Recurrent or persistent lameness at midterm remains an important finding in some cases despite good initial joint reduction, and good joint stability at short-term. Potential catastrophic complications may develop after surgery including extensive skin necrosis emphasizing the importance of regular rechecks until TESF removal.

\section{Conflict of Interest}

None declared. 


\section{References}

1 Kulendra E, Arthurs G. Management and treatment of feline tarsal injuries. In Pract 2014;36:119-132

2 Corr S. Intensive, extensive, expensive. Management of distal limb shearing injuries in cats. J Feline Med Surg 2009;11(09):747-757

3 Yardımcı C, Özak A, Önyay T, İnal KS. Management of traumatic tarsal luxations with transarticular external fixation in cats. Vet Comp Orthop Traumatol 2016;29(03):232-238

4 DeCamp CE, Johnston SA, Déjardin LM, Schaefer SL. 20 - Fractures and other orthopedic injuries of the tarsus, metatarsus, and phalanges. In: DeCamp CE, Johnston SA, Déjardin LM, Schaefer SL, eds. Brinker, Piermattei and Flo's Handbook of Small Animal Orthopedics and Fracture Repair (Fifth Edition). London, UK: W.B. Saunders; 2016:707-758

5 Roch SP, Störk CK, Gemmill TJ, Downes C, Pink J, McKee WM. Treatment of fractures of the tibial and/or fibular malleoli in 30 cats. Vet Rec 2009;165(06):165-170

6 Nicholson I, Langley-Hobbs S, Sutcliffe M, Jeffery N, Radke H. Feline talocrural luxation: a cadaveric study of repair using ligament prostheses. Vet Comp Orthop Traumatol 2012;25(02):116-125

7 Owen MA. Use of contoured bar transhock external fixators in 17 cats. J Small Anim Pract 2000;41(10):440-446

8 Luescher M, Schmierer PA, Park BH, et al. Biomechanical comparison of knotted and knotless stabilization techniques of the tarsal medial collateral ligament in cats: a cadaveric study. Vet Surg 2020;49:390-400

9 Johnston SA, Tobias KM. Tarsus and metatarsus. In: Veterinary Surgery: Small Animal. Vol 1;Second edition. Elsevier Health Sciences; 2017:1200-1203

10 Diamond DW, Besso J, Boudrieau RJ. Evaluation of joint stabilization for treatment of shearing injuries of the tarsus in 20 dogs. J Am Anim Hosp Assoc 1999;35(02):147-153

11 Aron DN, Purinton PT. Replacement of the collateral ligaments of the canine tarsocrural joint: a proposed technique. Vet Surg 1985; 14:178-184

12 Voss K, Langley-Hobbs SJ, Montavon PM. Tarsal joint. In: Montavon PM, Voss K, Langley-Hobbs SJ, eds. Feline Orthopedic Surgery and Musculoskeletal Disease. Edinburgh: W.B. Saunders; 2009:507-525

13 Fox SM, Guerin SR, Burbidge HM, Lindsay RG. Reconstruction of the medial collateral ligament for tarsocrural luxation in the dog: a preliminary study. J Am Anim Hosp Assoc 1997;33(03):268-274

14 Beever LJ, Kulendra ER, Meeson RL. Short and long-term outcome following surgical stabilization of tarsocrural instability in dogs. Vet Comp Orthop Traumatol 2016;29(02):142-148

15 Anderson DM, Langley-Hobbs SJ. Wounds and wound management. In: Langley-Hobbs SJ, Demetriou JL, Ladlow JF, eds. Feline Soft Tissue and General Surgery. W.B. Saunders; 2014:177-194

16 Jaeger GH, Wosar MA, Marcellin-Little DJ, Lascelles BDX. Use of hinged transarticular external fixation for adjunctive joint stabilization in dogs and cats: 14 cases (1999-2003). J Am Vet Med Assoc 2005;227(04):586-591

17 Kulendra E, Grierson J, Okushima S, Cariou M, House A. Evaluation of the transarticular external skeletal fixator for the treatment of tarsocrural instability in 32 cats. Vet Comp Orthop Traumatol 2011;24(05):320-325
18 Cook JL, Evans R, Conzemius MG, et al. Proposed definitions and criteria for reporting time frame, outcome, and complications for clinical orthopedic studies in veterinary medicine. Vet Surg 2010; 39(08):905-908

19 Gustilo RB, Anderson JT. Prevention of infection in the treatment of one thousand and twenty-five open fractures of long bones: retrospective and prospective analyses. J Bone Joint Surg Am 1976;58(04):453-458

20 Roe SC. Classification and nomenclature of external fixators. Vet Clin North Am Small Anim Pract 1992;22(01):11-18

21 Langley-Hobbs SJ, Meeson RL, Hamilton MH, Radke H, Lee K. Feline ilial fractures: a prospective study of dorsal plating and comparison with lateral plating. Vet Surg 2009;38(03):334-342

22 Burgess R, Elder S, McLaughlin R, Constable P. In vitro biomechanical evaluation and comparison of FiberWire, FiberTape, OrthoFiber, and nylon leader line for potential use during extraarticular stabilization of canine cruciate deficient stifles. Vet Surg 2010;39 (02):208-215

23 Voss K, Langley-Hobbs SJ, Montavon PM. Orthopedic implants. In: Voss K, Langley-Hobbs SJ, Montavon PM, eds. Feline Orthopedic Surgery and Musculoskeletal Disease. First edition. Edinburgh: W. B. Saunders; 2009:265-271

24 DeCamp CE, Johnston SA, Déjardin LcMa, Schaefer SL. External skeletal fixation. In: Brinker, Piermattei and Flo's Handbook of Small Animal Orthopedics and Fracture Repair. Fifth edition. 2016:66-95

25 Palmer RH, Hulse DA, Hyman WA, Palmer DR. Principles of bone healing and biomechanics of external skeletal fixation. Vet Clin North Am Small Anim Pract 1992;22(01):45-68

26 Bohling MW, Henderson RA. Differences in cutaneous wound healing between dogs and cats. Vet Clin North Am Small Anim Pract 2006;36(04):687-692

27 Bohling MW. Wound healing. In: Langley-Hobbs SJ, Demetriou JL, Ladlow JF, eds. Feline Soft Tissue and General Surgery. W.B. Saunders; 2014:171-175

28 Roch SP, Clements DN, Mitchell RA, et al. Complications following tarsal arthrodesis using bone plate fixation in dogs. J Small Anim Pract 2008;49(03):117-126

29 Meeson RL, Davidson C, Arthurs GI. Soft-tissue injuries associated with cast application for distal limb orthopaedic conditions. A retrospective study of sixty dogs and cats. Vet Comp Orthop Traumatol 2011;24(02):126-131

30 Anderson DM, White RA. Ischemic bandage injuries: a case series and review of the literature. Vet Surg 2000;29(06):488-498

31 Schwartz Z, Griffon D. Nonrigid external fixation of the elbow, coxofemoral, and tarsal joints in dogs. Compend Contin Educ Vet 2008;30(12):648-653

32 Lauer S, Hosgood G, Ramirez S, Lopez M. In vivo comparison of two hinged transarticular external skeletal fixators for multiple ligamentous injuries of the canine stifle. Vet Comp Orthop Traumatol 2008;21(01):25-35

33 Wiseman-Orr ML, Scott EM, Reid J, Nolan AM. Validation of a structured questionnaire as an instrument to measure chronic pain in dogs on the basis of effects on health-related quality of life. Am J Vet Res 2006;67(11):1826-1836 